\title{
A progression-free end-point for idiopathic pulmonary fibrosis trials: lessons from
}

\section{cancer}

\author{
Carlo Vancheri* and Roland M. du Bois ${ }^{\#}$
}

ABSTRACT: Idiopathic pulmonary fibrosis (IPF) is a progressive fibroproliferative disease that results in increasing morbidity. To date there is only one licensed therapy for this condition and other agents are needed for this attritional disease. Efforts to study other agents have been obstructed by an increasing division of opinion about the most clinically meaningful end-point of phase III clinical trials to demonstrate efficacy. Many clinicians believe that an agent that impedes progression of the disease is more than acceptable and will encourage the pharmaceutical industry to further develop their IPF programmes. We have been impressed by the behavioural and biological similarities of cancer and IPF, and wondered if lessons could be learned about clinical trial design from lung cancer studies. Here, we set out our arguments that the similarities with cancer justify comparing the magnitude of therapeutic effects in clinical trials in nonsmall cell lung cancer with those in successful trials in IPF. We demonstrate that efficacy is of a similar magnitude in the two chronic lung diseases. We recommend that the demonstration of similar magnitudes of progression-free disease effect in IPF, using appropriate indices, should be considered as clinically meaningful benefit in future phase III clinical trials of novel therapies.

KEYWORDS: Clinical trials, fibroblast/myofibroblast, forced vital capacity, lung cancer, pulmonary fibrosis, pulmonary function tests

diopathic pulmonary fibrosis (IPF) is a progressive fibroproliferative disease characterised by an accumulation of myofibroblasts in the alveolar wall, aberrant matrix deposition and subsequent distortion of the normal lung architecture. The disease results in progressive morbidity, worsening quality of life and an increasing dependence on others for the most basic of functional needs. The current paradigm of the pathogenetic process that results in IPF is that the disease is initiated by recurrent injury to the alveolar epithelium and evolves into an aberrant fibroproliferative response which progresses [1]. The cause(s) of the repeated injury is unknown but is thought to be the product of one or more environmental triggers operating within an individual whose genotype makes them susceptible to the disease [2]. More recently, IPF has been assimilated to a neoproliferative disorder based on the evidence that a number of pathogenic features of IPF are shared with cancer biology [3]. Genetic and epigenetic changes, delayed apoptosis and altered response to regulatory signals by myofibroblasts, reduced cellular communications and abnormal activation of specific signalling pathways have been shown to be hallmarks common to IPF and cancer. Consistent with this, Cool et al. [4] reported that "fibroblast foci", the characteristic defining lesions in IPF, are interconnected, forming a three-dimensional reticulum that resembles the tissue infiltration typical of cancer. The absence of monoclonality noted within the fibroblast foci and their incapacity to metastasise do not preclude the concept that IPF exhibits a cancer-like nature, given that neoplastic disorders such as desmoid tumours infiltrate tissue locally without metastasis and that several cancers are not monoclonal $[5,6]$. Consistent with the cancer-like biology in IPF, the survival of IPF patients is poor, with a 5 -yr survival rate $<30 \%[7,8]$. This figure is consistent across several studies and is worse than that seen in many types of cancer (fig. 1).

At present, there are few treatment options for patients with IPF and none in the USA. The challenges inherent in finding completely effective
AFFILIATIONS

*Dept of Clinical and Molecular Biomedicine, University of Catania, Catania, Italy.

\#National Heart \& Lung Institute, Imperial College, London, UK.

\section{CORRESPONDENCE}

C. Vancheri

Regional Center for Interstitial and

Rare Lung Diseases

University of Catania

Via S. Sofia 78

95123 Catania

Italy

E-mail: vancheri@unict.it

Received:

July 242012

Accepted after revision:

Aug 052012

First published online:

Aug 162012 


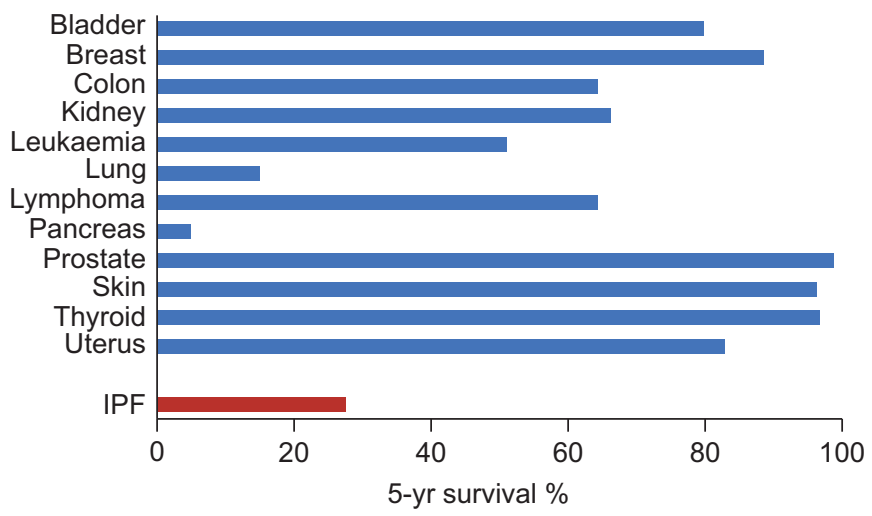

FIGURE 1. 5-yr survival rate for idiopathic pulmonary fibrosis (IPF) and for different cancers. Reproduced and modified from [3].

agents have been addressed in a number of recent reviews [913]. Part of the problem is disagreement about how to judge drug efficacy. Given the biological and behavioural similarities with cancer, we believe that the lack of a pipeline of new therapies for IPF is problematic and we believe that we need to rethink the approach to finding better treatments. If a disease has similarities with cancer, perhaps we can learn from trials of therapy for lung cancer. The mission of this article is, therefore, to present a reasoned argument in support of the view that clinical trials in IPF should follow the cancer model of trials of novel therapy by using progression-free survival as a logical and clinically meaningful end-point. At present, there is much debate on this issue, which is in danger of derailing what, at present, is an important momentum in drug development for this lethal disease. The three pillars on which our argument is based are: 1) the similarities between IPF and cancer biology, and the associated similar rate of mortality between IPF and many cancers; 2) the current uncertainty about how to measure efficacy in phase III clinical trials of novel therapy; and 3) evidence from recently published IPF trials that show a similar reduction in the rate of disease progression of those individuals on active therapy, comparable in magnitude to that seen in trials of therapies for nonsmall cell lung cancer (NSCLC).

\section{THE SIMILARITIES BETWEEN IPF AND CANCER BIOLOGY}

It is now generally accepted that the pathogenetic process in IPF is the result of repeated injury to the alveolar epithelium over a prolonged time period, which results in the activation of a number of processes, including increased procoagulant activity, impaired matrix turnover, fibroblast activation and transition to myofibroblasts, with the end result being progressive and generally irreversible fibrosis. This process is very reminiscent of what takes place during normal wound healing, with the difference being that in IPF the final result is abnormal tissue repair and fibrosis. Quite what prevents the wound from healing normally in IPF is unknown. Interestingly, abnormal wound repair and cancer also share a number of similarities in terms of cell proliferation, survival, invasiveness, signalling pathways, gene expression and angiogenic signals, to the extent that some authors have defined cancer as wounds that do not heal [14-16]. It is obvious that these changes are transient and self-limiting during normal wound healing, whereas cancer and fibrosis inexorably progress, infiltrating the surrounding tissues. Consistent with this, CoOL et al. [4] described "fibroblast foci", the characteristic, defining lesions in IPF, not as isolated aggregates of myofibroblasts, but instead as being interconnected, forming a three-dimensional reticulum that extends throughout the lungs and the pleural surface, reminiscent of the tissue infiltration typical of cancer. To establish whether this reticulum is benign or malignant, CoOL et al. [4] analysed the clonal pattern of the IPF fibroblasts that comprise the foci. Based on the absence of monoclonality, observed within the fibroblast foci, they opted to define the lesions as reactive and nonmalignant [4]. In this regard, it is a prevalent view that cancers are always of monoclonal origin, since it is believed that they develop from a single transformed cell. However, a number of studies have shown that only some cancers are monoclonal for the entire course of the disease while many of them are characterised by cytogenetic heterogeneity. Some cancers are initially monoclonal then acquire clonal heterogeneity; others have a polyclonal origin, becoming monoclonal over time; and some are first polyclonal, temporarily assume a monoclonal pattern, reverting later to polyclonality [17]. These phenomena of clonal convergence and clonal divergence, quite common in cancer, challenge the "dogma" of monoclonality being a defining characteristic of cancer and allow the consideration that the fibroblast reticulum described by CoOL et al. [4] may indeed be consistent with a cancer-like process. However, in addition to the lack of fibroblast monoclonality, other arguments raise doubts about the concept of the cancer-like nature of IPF, including the absence of metastasis and the invariant bilateral nature of IPF. In our opinion, the inability to metastasise does not exclude the cancer-like nature of IPF given that neoplastic disorders such as desmoid tumours are characterised by fibroblast proliferation and local tissue infiltration without metastasis, and cancers not uncommonly present simultaneously in both lungs, both breasts or both kidneys [18-21].

Consistent with this hypothesis of cancer-like behaviour, IPF also resembles many cancers with regard to its poor response to treatment, and the more common pattern of disease progression leading to death, in many cases at a rate that exceeds many cancers [3]. In addition to these similarities of tissue infiltration and response to therapy, IPF and cancer also share a number of cell and molecular aberrances including genetic and epigenetic changes, impaired cellular communication, altered response to regulatory signals by myofibroblasts, and abnormal activation of specific signalling pathways, all of which contribute to the relentless progression of the disorders in question.

\section{GENETIC AND EPIGENETIC ABNORMALITIES}

A number of abnormalities in tumour suppression genes, microsatellite instability, loss of heterozygosity, telomere biology and aberrant apoptotic mechanisms have been reported in both cancer and IPF. These mechanisms are reported in detail in a previous review by VANCHERI et al. [3] and will just be summarised here. Variants of tumour suppressor genes, such as those encoding p53 (TP53) and fragile histidine triad (FHIT), affect the control of cell proliferation and apoptosis in some cancers, and the same alterations have been described in IPF, specifically in the peripheral honeycomb areas, the characteristic histopathological lesions of the disease [22-25]. Other, more specific mutations are common to cancer and IPF: microsatellite 
instability and loss of heterozygosity observed in $\sim 50 \%$ of IPF patients; telomere shortening and mutations of genes affecting telomerase expression [26-28]; and epigenetic alterations in key regulatory genes in response to environmental exposure, tobacco smoke, diet and ageing. In this regard, RABINOVICH et al. [29] have recently shown that global methylation patterns in IPF are different from those of control tissues and have some similarity to cancer. In IPF tissue, there is a reduced expression of the glycoprotein Thy-1, normally expressed by fibroblasts, due to the hypermethylation of the Thy-1 promoter region [30, 31]. The loss of this molecule is linked to the transformation of fibroblasts into myofibroblasts within "fibroblast foci"; whereas in cancer, it is associated with more invasive behaviour of the disease. More recently, the abnormal expression of microRNAs (miRNAs) has been also associated with the pathogenesis of both cancer and IPF. miRNAs are short non-protein coding RNAs, involved in the regulation of different processes essential for carcinogenesis, such as tumour growth, invasion and metastasis [32-34]. Another feature in cancer patients is the presence of elevated blood levels of cell-free DNA. Cell-free DNA often presents the same genetic and/or epigenetic changes observed in the DNA of related cancers and, for this reason, is considered a potential diagnostic and prognostic biomarker of cancer [35]. Interestingly, CASONI et al. [36] showed significant higher levels of free circulating DNA in patients affected by IPF compared with healthy subjects and other fibrotic diffuse lung diseases such as nonspecific pulmonary fibrosis, suggesting a role for cell-free DNA in discriminating IPF from other fibrotic lung disorders. Taken together, these similarities in genetic and epigenetic variants provide support for considering IPF to be more neoplastic in biological behaviour than previously considered.

\section{ALTERED CELL-CELL COMMUNICATIONS}

Cell-cell communications are facilitated by gap junctions that are essential for co-ordinated tissue function. Connexin $(\mathrm{Cx})$ molecules provide the infrastructure for gap junctions that synchronise biological activities such as proliferation and tissue repair. In the lung, Cx43 plays a central role in the regulation of intercellular communications and, although particularly expressed by lung fibroblasts, is considered the major connexin functionally connecting airway, alveolar and endothelial cells [37]. A number of studies have shown a reduced expression of connexins, including Cx43 in some cancers and a subsequent reduction of intercellular communication [38]. The concept of considering both cancer and IPF to share mechanisms closely related to wound healing is also sustained by the involvement of $\mathrm{Cx} 43$ in the reparative process that takes place during wound healing. The downregulation, with antisense oligodeoxynucleotides, of the expression of this connexin increases cell proliferation and migration of keratinocytes and fibroblasts, accelerating wound repair at skin wound sites, while the reduction of $\mathrm{Cx} 43$, in an in vitro model of fibroblast wound-healing, leads to increased expression of transforming growth factor (TGF)- $\beta$, collagen production, myofibroblast differentiation and, hence, to a faster healing process. It is perhaps counterintuitive to suggest that a process that accelerates wound healing might also be responsible for the aberrant wound healing that characterises IPF. However, if the downregulation of Cx43 accelerates wound healing, it is possible that imprecise control of this accelerating process could result in the unfettered fibroblast proliferation that characterises abnormal repair, fibrosis and cancer. In support of this hypothesis, fibroblasts from keloids and hypertrophic scars express significantly lower levels of Cx43 compared to those from normal skin tissue [39]. We have shown that in primary lung fibroblasts from IPF patients there is also a reduced expression of Cx43 that resulted in a reduced gap junctional intercellular communication in fibrotic fibroblasts compared to normal cells. The reduced cell-cell communication described in IPF fibroblasts is very similar to that which has been described in cancer cells and may give an explanation for the release from the restraint of contact inhibition and uncontrolled proliferation that is present in both these diseases [40].

\section{ALTERED RESPONSE TO REGULATORY SIGNALS BY MYOFIBROBLASTS}

During wound healing, myofibroblasts actively participate in tissue repair and, when the wound edges become apposed, they progressively disappear through apoptosis [41]. In some circumstances, due to an altered function of the apoptotic process, myofibroblasts evade programmed cell death, causing excessive scarring and fibrosis. Abnormal wound healing and exaggerated myofibroblast activation underlie other conditions characterised by an uncontrolled proliferation of myofibroblasts including fibromatosis, inflammatory myofibroblastic tumours, and myofibroblastic cancers such as myofibromas and myofibroblastomas [42]. It is also becoming evident that tumour progression and infiltration of tissues by cancer cells is made easier by the activity of those myofibroblasts that encircle cancerous lesions. Cancer-associated fibroblasts may in fact produce a number of mediators and growth factors that directly promote cancer progression [41]. In primary and metastatic cancers, TGF- $\beta$ produced by cancer-derived epithelial cells is responsible for the emergence of myofibroblasts at the invasive front of the tumour and protects these cells from apoptosis. Myofibroblasts in turn produce additional TGF- $\beta$, other inflammatory mediators and metalloproteinases that, by disrupting the basement membrane of the surrounding tissues, may facilitate cancer invasiveness. Indeed, cancer progression has been related to the expression of TGF- $\beta$ and metalloproteinases expressed by cancer cells and their increased levels are considered a negative prognostic factor of survival in many cancers including lung cancer [43]. Similar to cancer cells, myofibroblasts in IPF may sustain their own growth in an autocrine process stimulated by fibrogenic cytokines such as TGF- $\beta$ and by losing, at least in part, the ability to produce the antifibrotic prostaglandin ( $\mathrm{PG}) \mathrm{E}_{2}$ [44]. The controlling activity of $\mathrm{PGE}_{2}$ is further diminished by the reduced expression in IPF tissues of the E prostanoid receptor $2[45,46]$. Tumour progression also depends on the expression of a series of molecules that are able to facilitate cancer invasion, including laminin, heat shock protein (hsp)27 and fascin [47-49]. Interestingly, in IPF, it has been shown that epithelial cells surrounding fibroblast foci express large amounts of laminin, fascin and hsp27. These molecules were exclusively expressed by bronchiolar basal cells layered between luminal epithelial cells on one side and myofibroblasts on the other [50]. The expression of molecules so involved in both cell migration and invasion in bronchiolar basal cells adjacent to myofibroblasts at the same time facing the luminal epithelium is very reminiscent of what has already been described in cancer where these molecules are expressed at the invasive front of carcinomas. 


\section{ABNORMAL ACTIVATION OF SPECIFIC SIGNALLING PATHWAYS}

The Wnt/ $\beta$-catenin signalling pathway regulates the expression of molecules involved in tissue invasion, such as matrilysin, laminin and cyclin-D1, and most importantly is involved in a biologically relevant cross-talk with TGF- $\beta$. It is well known that this pathway is abnormally activated in several human cancers, including lung cancer, mesothelioma and desmoid tumours [51]. More recently, an activation of the $\mathrm{Wnt} / \beta$-catenin pathway has been also described in different fibroproliferative disorders of the liver and kidney [52]. In regard to this, CHILOSI et al. [53] have shown that the Wnt/ $\beta$-catenin pathway is strongly activated in IPF lung tissues as demonstrated by the presence of an intense immunoreactivity for $\beta$-catenin and a contemporary expression of high levels of two downstream genes of the Wnt/ $\beta$-catenin pathway, cyclin-D1 and matrilysin. The Wnt pathway may also be activated by the fibrogenic cytokine TGF- $\beta$ [54]. The transcription of extracellular signal-regulated kinase $1 / 2$ target gene, induced by TGF- $\beta$, could also lead to a secondary activation of other signalling pathways such as the phosphatidylinositol 3-kinase/Akt pathway that may regulate cell proliferation and apoptosis $[55,56]$. Failure to activate the apoptotic programme may represent an important step in the abnormal repair that characterises lung fibrosis and cancer by protecting fibroblasts from apoptosis.

\section{THE CURRENT UNCERTAINTY ABOUT HOW TO MEASURE EFFICACY IN TRIALS OF NOVEL THERAPY}

In trials of therapy for IPF, numerous end-points have been chosen to assess efficacy, reflecting the uncertainty about the best way to judge whether or not an agent is affecting the disease process (table 1). This situation has been eased recently by the publication of several positive studies that have utilised forced vital capacity (FVC) or vital capacity (VC) as a logical end-point, given that it is a measure of how the individual's function has been affected and, importantly, a measure that has been shown to be amenable to therapy $[60,61,63,70,72,73]$. Additionally, recent studies evaluating the measurement characteristics of FVC have confirmed it to be a robust measurement in patients with IPF [74, 75]. Finally, in addition to statistically significant effects on the mean change in FVC, recent therapeutic trials demonstrated that disease progression, assessed by categorical changes in FVC or $\mathrm{VC}$, is also improved by treatment. It would seem to the authors that any therapy that diminishes the rate of progression of this attritional disease has some merit and it is unclear why this view is not unanimous within the IPF clinical community. However, there is a continuing groundswell of opinion criticising most endpoints that are currently being used to assess efficacy [70]. The debate centres on what end-points are clinically meaningful. Implicit in the debate on the designation of an end-point as clinically meaningful is the determination of what magnitude of therapeutic effect on a chosen end-point represents a clinically meaningful benefit. Most end-points that have been utilised over the last 8 yrs, including numerous measures of lung function e.g. FVC, transfer capacity of carbon monoxide, distance walked in $6 \mathrm{~min}$ and combinations of these, have been dismissed by these authors as being unacceptable for a variety of reasons. The authors have concluded that all-cause survival and hospitalisations are the recommended end-points [76]. While these indices have their merits, there are logistic and other problems in designing studies with these indices as outcome measures. Retaining the large numbers of patients that would need to be enrolled and followed for sufficiently long periods to obtain the required number of events to prove a mortality effect is problematic. The reasons for hospitalisations are varied, not always directly related to the lung fibrosing process and could not, therefore, be expected to be reduced in numbers by a drug that targets the fibrosing process. In this context, it seems reasonable to explore end-points that directly measure an effect on progression of disease using clinically meaningful indices including lung function, especially FVC, where a magnitude of clinically meaningful benefit can also be defined and demonstrated.

TABLE 1 Primary end-points used in clinical trials, 2004-2012

\begin{tabular}{|c|c|c|c|c|c|c|c|c|}
\hline Nотн [57] & + & & & & & + & + & \\
\hline KING [59] & & & & & & & & + \\
\hline RICHELDI [60] & + & & & & & & & \\
\hline Noble [61] & + & & & & & & & \\
\hline DANIELS [64] & & & & & & & & + \\
\hline KING [65] & & & & & & + & & \\
\hline RAGHU [66] & + & & + & + & & & & \\
\hline KING [67] & & & & & + & & & \\
\hline КUво [68] & & & & & & + & + & \\
\hline
\end{tabular}

FVC: forced vital capacity; VC: vital capacity; DL,CO: diffusing capacity of the lung for carbon monoxide; 6MWT: 6-min walk test; PFS: progression-free survival. 

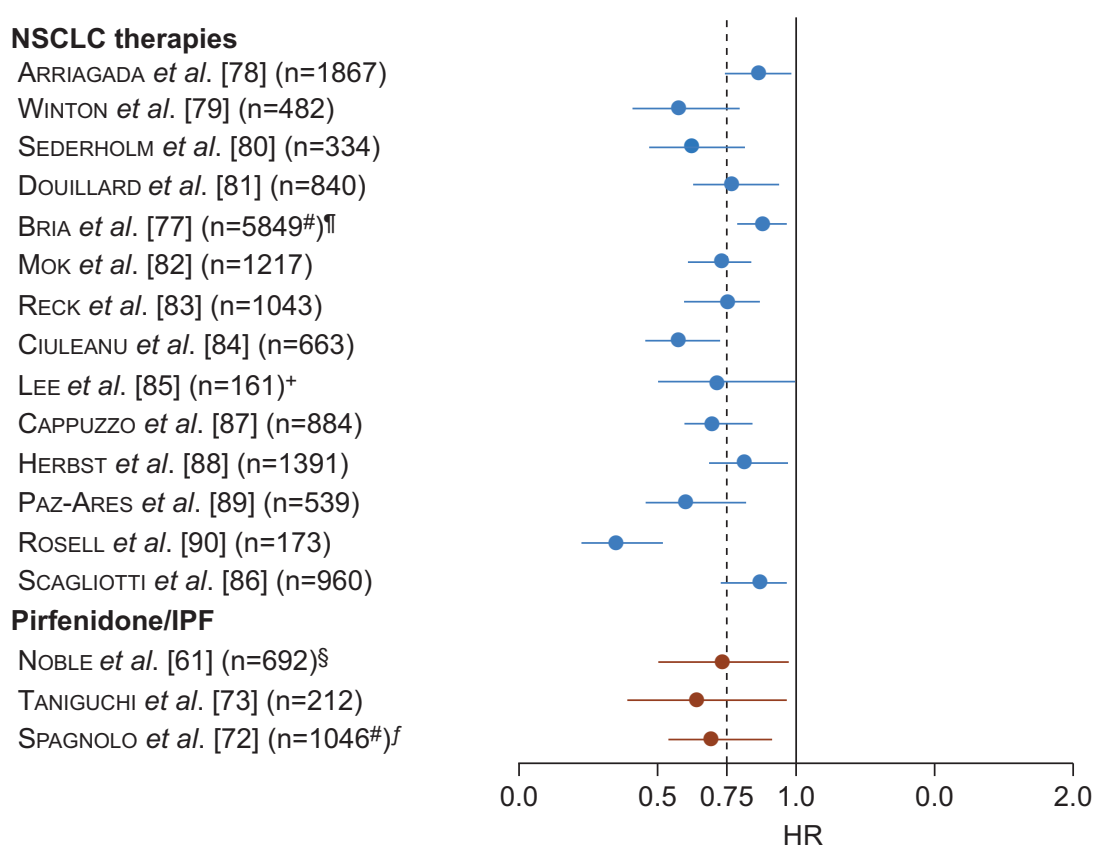

FIGURE 2. Hazard ratio (HR) for progression-free survival time in randomised controlled trials evaluating therapies for nonsmall cell lung cancer (NSCLC) and idiopathic pulmonary fibrosis (IPF). Whiskers represent 95\% confidence intervals, unless otherwise stated. (Adapted from [80].) ${ }^{\#}$ : meta analysis; ": reported as relative risk (95\% Cl) +: reported as $\mathrm{HR}(90 \% \mathrm{Cl}) ;{ }^{\text {s: }}$ : analysis of pooled data from Study 004 and Study 006; ${ }^{f}$ : analysis of data from the three phase III trials of pirfenidone in IPF

\section{PROGRESSION-FREE SURVIVAL IN THERAPEUTIC TRIALS IN NSCLC AS A BENCHMARK FOR ASSESSING CLINICAL BENEFIT IN IPF CLINICAL TRIALS}

We argue that these challenges to trial design are not dissimilar to those experienced by oncologists, who are now using progression-free survival as an acceptable index of therapeutic efficacy in clinical trials evaluating new therapies. While we would not wish to imply that IPF is the same as lung cancer, we believe, as discussed, that there are sufficient similarities in biology and clinical behaviour to justify a comparison of the magnitude of effects on disease progression of lung cancer therapies with the magnitude of effect observed in recent trials evaluating IPF therapies.

In a meta analysis of clinical trials of adjuvant therapy regimens in NSCLC involving >7,000 individuals, first published online in 2008, significant improvements in disease-free survival were demonstrated with relative risks ranging from 0.88 to 0.89 [77]. A more recent literature search of all randomised controlled trials that studied novel adjuvant therapies for patients with NSCLC showed that in 14 studies involving $>15,000$ patients [78-91], a statistically significant treatment effect on progression-free survival was seen with hazard ratios ranging from 0.6 to 0.83 , with a single exception [90] in which the hazard ratio in favour of therapy was reduced to 0.37 .

In light of the biological and behavioural similarities between IPF and cancer, and the widespread utilisation of progressionfree survival in cancer trials, it is interesting to note that an independent meta-analysis of the magnitude of effect on progression-free survival of the novel agent pirfenidone in the three phase III IPF studies [60, 61, 63, 70, 72], performed under the aegis of the Cochrane collaboration [72], showed a hazard ratio of 0.7, favouring pirfenidone. This magnitude of progression-free survival benefit, is, therefore, strikingly similar to that seen in NSCLC trials. Importantly, the use of progressionfree survival in cancer has allowed different treatment regimens and different combinations of drugs to be evaluated using the same standard index of efficacy. This is the position that we need to occupy for future drug development in IPF, where even relatively small increases in time to progression might be enough, for example, to provide a bridge to transplantation. Figure 2 demonstrates the similarity in magnitude of treatment effect on progression-free survival in clinical trials evaluating treatments for NSCLC compared with the observed effect of pirfenidone in recent trials in patients with IPF. This would appear to support strongly the concept of using appropriate indices of progression that are clinically meaningful to demonstrate the same magnitude of progression-free disease benefit in IPF trials which has been commonly accepted as being of clinically meaningful benefit in studies in NSCLC.

\section{SUMMARY}

In summary, the cancer-like outcomes in IPF, the commonality of pathobiological paradigms between IPF and cancer, the outcome of studies of progression-free survival in IPF and how they compare with effects of treatment on magnitude of progression-free survival in cancer trials present, we believe, a robust case for concluding that magnitudes of progression-free disease benefit in IPF, similar to those seen in NSCLC, should be regarded as a successful outcome of clinical trials of novel therapy.

\section{STATEMENT OF INTEREST}

Statements of interest for C. Vancheri and R.M. du Bois can be found at www.erj.ersjournals.com/site/misc/statements.xhtml 


\section{REFERENCES}

1 Selman M, King TE, Pardo A. Idiopathic pulmonary fibrosis: prevailing and evolving hypotheses about its pathogenesis and implications for therapy. Ann Intern Med 2001; 134: 136-151.

2 Seibold MA, Schwartz DA. The lung: the natural boundary between nature and nurture. Ann Rev Physiol 2011; 73: 457-478.

3 Vancheri C, Failla M, Crimi N, et al. Idiopathic pulmonary fibrosis: a disease with similarities and links to cancer biology. Eur Respir J 2010; 35: 496-504.

4 Cool CD, Groshong SD, Rai PR, et al. Fibroblast foci are not discrete sites of lung injury or repair: the fibroblast reticulum. Am J Respir Crit Care Med 2006; 174: 654-658.

5 Kotiligam D, Lazar AJ, Pollock RE, et al. Desmoid tumor: a disease opportune for molecular insights. Histol Histopathol 2008; 23: 117-126.

6 Parsons BL. Many different tumor types have polyclonal tumor origin: evidence and implications. Mutat Res 2008; 659: 232-247.

7 Nicholson AG, Colby TV, du Bois RM, et al. The prognostic significance of the histologic pattern of interstitial pneumonia in patients presenting with the clinical entity of cryptogenic fibrosing alveolitis. Am J Respir Crit Care Med 2000; 162: 2213-2217.

8 Daniil ZD, Gilchrist FC, Nicholson AG, et al. A histologic pattern of nonspecific interstitial pneumonia is associated with a better prognosis than usual interstitial pneumonia in patients with cryptogenic fibrosing alveolitis. Am J Respir Crit Care Med 1999; 160: 899-905.

9 Costabel U. Emerging potential treatments: new hope for idiopathic pulmonary fibrosis patients? Eur Respir Rev 2011; 20: 201-207.

10 Albera C. Challenges in idiopathic pulmonary fibrosis trials: the point on end-points. Eur Respir Rev 2011; 20: 195-200.

11 Nathan SD, du Bois RM. Idiopathic pulmonary fibrosis trials: recommendations for the jury. Eur Respir J 2011; 38: 1002-1004.

12 Cottin V. Changing the idiopathic pulmonary fibrosis treatment approach and improving patient outcomes. Eur Respir Rev 2012; 21: 161-167.

13 Richeldi L. Assessing the treatment effect from multiple trials in idiopathic pulmonary fibrosis. Eur Respir Rev 2012; 21: 147-151.

14 Dvorak HF. Tumors: wounds that do not heal. Similarities between tumor stroma generation and wound healing. $N$ Engl J Med 1986; 315: 1650-1659.

15 Haddow A. Molecular repair, wound healing, and carcinogenesis: tumor production a possible overhealing? Adv Cancer Res 1972; 16 181-234.

16 Riss J, Khanna C, Koo S, et al. Cancers as wounds that do not heal: differences and similarities between renal regeneration/repair and renal cell carcinoma. Cancer Res 2006; 66: 7216-7224.

17 Teixeira MR, Heim S. Cytogenetic analysis of tumor clonality. Adv Cancer Res 2011; 112: 127-149.

18 Shah AA, Barfield ME, Kelsey CR, et al. Outcomes after surgical management of synchronous bilateral primary lung cancers. Ann Thorac Surg 2012; 93: 1055-1060.

19 Trousse D, Barlesi F, Loundou A, et al. Synchronous multiple primary lung cancer: an increasing clinical occurrence requiring multidisciplinary management. J Thorac Cardiovasc Surg 2007; 133 1193-1200.

20 Kwast $\mathrm{AB}$, Liu L, Roukema JA, et al. Increased risks of third primary cancers of non-breast origin among women with bilateral breast cancer. Br J Cancer 2012; 107: 549-555.

21 Shuch B, Singer EA, Bratslavsky G. The surgical approach to multifocal renal cancers: hereditary syndromes, ipsilateral multifocality, and bilateral tumors. Urol Clin North Am 2012; 39: 133-148.

22 Kuwano K, Kunitake R, Kawasaki M, et al. p21Waf1/Cip1/Sdi1 and p53 expression in association with DNA strand breaks in idiopathic pulmonary fibrosis. Am J Respir Crit Care Med 1996; 154 477-483.
23 Hojo S, Fujita J, Yamadori I, et al. Heterogeneous point mutations of the p53 gene in pulmonary fibrosis. Eur Respir J 1998; 12: 1404-1408.

24 Uematsu K, Yoshimura A, Gemma A, et al. Aberrations in the fragile histidine triad (FHIT) gene in idiopathic pulmonary fibrosis. Cancer Res 2001; 61: 8527-8533.

25 Demopoulos K, Arvanitis DA, Vassilakis DA, et al. MYCL1, FHIT, SPARC, P16(INK4) and TP53 genes associated to lung cancer in idiopathic pulmonary fibrosis. J Cell Mol Med 2002; 6: 215-222.

26 Cronkhite JT, Xing C, Raghu G, et al. Telomere shortening in familial and sporadic pulmonary fibrosis. Am J Respir Crit Care Med 2008; 178: 729-737.

27 Diaz de Leon A, Cronkhite JT, Katzenstein AL, et al. Telomere lengths, pulmonary fibrosis and telomerase (TERT) mutations. PLoS One 2010; 5: e10680.

28 Liu T, Chung MJ, Ullenbruch M, et al. Telomerase activity is required for bleomycin-induced pulmonary fibrosis in mice. J Clin Invest 2007; 117: 3800-3809.

29 Rabinovich EI, Kapetanaki MG, Steinfeld I, et al. Global methylation patterns in idiopathic pulmonary fibrosis. PLoS One 2012; 7 e33770.

30 Sanders YY, Kumbla P, Hagood JS. Enhanced myofibroblastic differentiation and survival in Thy-1 lung fibroblasts. Am J Respir Cell Mol Biol 2007; 36: 226-235.

31 Sanders YY, Pardo A, Selman M, et al. Thy-1 promoter hypermethylation: a novel epigenetic pathogenic mechanism in pulmonary fibrosis. Am J Respir Cell Mol Biol 2008; 39: 610-618.

32 Lovat F, Valeri N, Croce CM. MicroRNAs in the pathogenesis of cancer. Semin Oncol 2011; 38: 724-733.

33 Oak SR, Murray L, Herath A, et al. A micro RNA processing defect in rapidly progressing idiopathic pulmonary fibrosis. PLoS One 2011; 6: e21253.

34 Pandit KV, Milosevic J, Kaminski N. MicroRNAs in idiopathic pulmonary fibrosis. Transl Res 2011; 157: 191-199.

35 Schwarzenbach H, Hoon DS, Pantel K. Cell-free nucleic acids as biomarkers in cancer patients. Nat Rev Cancer 2011; 11: 426-437.

36 Casoni GL, Ulivi P, Mercatali L, et al. Increased levels of free circulating DNA in patients with idiopathic pulmonary fibrosis. Int J Biol Markers 2010; 25: 229-235.

37 Losa D, Chanson M, Crespin S. Connexins as therapeutic targets in lung disease. Expert Opin Ther Targets 2011; 15: 989-1002.

38 Cesen-Cummings K, Fernstrom MJ, Malkinson AM, et al. Frequent reduction of gap junctional intercellular communication and connexin43 expression in human and mouse lung carcinoma cells. Carcinogenesis 1998; 19: 61-67.

39 Mori R, Power KT, Wang CM, et al. Acute downregulation of connexin 43 at wound sites leads to a reduced inflammatory response, enhanced keratinocyte proliferation and wound fibroblast migration. J Cell Sci 2006; 119: 5193-5203.

40 Trovato-Salinaro A, Trovato-Salinaro E, Failla M, et al. Altered intercellular communication in lung fibroblast cultures from patients with idiopathic pulmonary fibrosis. Respir Res 2006; 7: 122.

41 Desmouliere A, Guyot C, Gabbiani G. The stroma reaction myofibroblast: a key player in the control of tumor cell behavior. Int J Dev Biol 2004; 48: 509-517.

42 Fletcher CD. Myofibroblastic tumours: an update. Verh Dtsch Ges Pathol 1998; 82: 75-82.

43 Micke P, Ostman A. Tumour-stroma interaction: cancer-associated fibroblasts as novel targets in anti-cancer therapy? Lung Cancer 2004; 45: Suppl. 2, S163-S175.

44 Vancheri C, Sortino MA, Tomaselli V, et al. Different expression of TNF- $\alpha$ receptors and prostaglandin $\mathrm{E}_{2}$ production in normal and fibrotic lung fibroblasts: potential implications for the evolution of the inflammatory process. Am J Respir Cell Mol Biol 2000; 22: 628-634.

45 McAnulty RJ, Hernandez-Rodriguez NA, Mutsaers SE, et al. Indomethacin suppresses the anti-proliferative effects of transforming 
growth factor- $\beta$ isoforms on fibroblast cell cultures. Biochem J 1997; 321: 639-43.

46 Moore BB, Ballinger MN, White ES, et al. Bleomycin-induced E prostanoid receptor changes alter fibroblast responses to prostaglandin E2. J Immunol 2005; 174: 5644-5649.

47 Moriya $\mathrm{Y}$, Niki T, Yamada $\mathrm{T}$, et al. Increased expression of laminin-5 and its prognostic significance in lung adenocarcinomas of small size. An immunohistochemical analysis of 102 cases. Cancer 2001; 91: 1129-1141.

48 Garrido C, Schmitt E, Cande C, et al. HSP27 and HSP70: potentially oncogenic apoptosis inhibitors. Cell Cycle 2003; 2: 579-584.

49 Pelosi G, Pastorino U, Pasini F, et al. Independent prognostic value of fascin immunoreactivity in stage I nonsmall cell lung cancer. $\mathrm{Br}$ J Cancer 2003; 88: 537-547.

50 Chilosi M, Zamo A, Doglioni C, et al. Migratory marker expression in fibroblast foci of idiopathic pulmonary fibrosis. Respir Res 2006; 7: 95.

51 Mazieres J, He B, You L, et al. Wnt signaling in lung cancer. Cancer Lett 2005; 222: 1-10.

52 Bowley E, O'Gorman DB, Gan BS. $\beta$-Catenin signaling in fibroproliferative disease. J Surg Res 2007; 138: 141-150.

53 Chilosi M, Poletti V, Zamo A, et al. Aberrant Wnt/ $\beta$-catenin pathway activation in idiopathic pulmonary fibrosis. Am J Pathol 2003; 162: 1495-1502.

54 Caraci F, Gili E, Calafiore M, et al. TGF- $\beta 1$ targets the GSK-3 $\beta / \beta$ catenin pathway via ERK activation in the transition of human lung fibroblasts into myofibroblasts. Pharmacol Res 2008; 57: 274-282.

55 Tian B, Lessan K, Kahm J, et al. $\beta 1$ integrin regulates fibroblast viability during collagen matrix contraction through a phosphatidylinositol 3-kinase/Akt/protein kinase B signaling pathway. J Biol Chem 2002; 277: 24667-24675.

56 Conte E, Fruciano M, Fagone E, et al. Inhibition of PI3K prevents the proliferation and differentiation of human lung fibroblasts into myofibroblasts: the role of class I P110 isoforms. PLOS ONE 2011; 6: e24663.

57 Noth I, Anstrom KJ, Calvert SB, et al. A placebo-controlled randomized trial of warfarin in idiopathic pulmonary fibrosis. Am J Respir Crit Care Med 2012; 186: 88-95.

58 Raghu G, Anstrom KJ, King TE Jr, et al. Prednisone, azathioprine, and N-acetylcysteine for pulmonary fibrosis. N Engl J Med 2012; 366: 1968-1977.

59 King TE Jr, Brown KK, Raghu G, et al. BUILD-3: a randomized, controlled trial of bosentan in idiopathic pulmonary fibrosis. Am J Respir Crit Care Med 2011; 184: 92-99.

60 Richeldi L, Costabel U, Selman M, et al. Efficacy of a tyrosine kinase inhibitor in idiopathic pulmonary fibrosis. N Engl J Med 2011; 365: 1079-1087.

61 Noble PW, Albera C, Bradford WZ, et al. Pirfenidone in patients with idiopathic pulmonary fibrosis (CAPACITY): two randomised trials. Lancet 2011; 377: 1760-1769.

62 Zisman DA, Schwarz M, Anstrom KJ, et al. A controlled trial of sildenafil in advanced idiopathic pulmonary fibrosis. $N$ Engl J Med 2010; 363: 604-628.

63 Taniguchi H, Ebina M, Kondoh $\mathrm{Y}$, et al. Pirfenidone in idiopathic pulmonary fibrosis. Eur Respir J 2010; 35: 821-829.

64 Daniels CE, Lasky JA, Limper AH, et al. Imatinib treatment for idiopathic pulmonary fibrosis: randomized placebo-controlled trial results. Am J Respir Crit Care Med 2010; 181: 604-610.

65 King TE Jr, Albera C, Bradford WZ, et al. Effect of interferon $\gamma-1 \mathrm{~b}$ on survival in patients with idiopathic pulmonary fibrosis (INSPIRE): a multicentre, randomised, placebo-controlled trial. Lancet 2009; 374: 222-228.

66 Raghu G, Brown KK, Costabel U, et al. Treatment of idiopathic pulmonary fibrosis with etanercept: an exploratory, placebocontrolled trial. Am J Respir Crit Care Med 2008; 178: 948-955.
67 King TE Jr, Behr J, Brown KK, et al. BUILD-1: a randomized placebo-controlled trial of bosentan in idiopathic pulmonary fibrosis. Am J Respir Crit Care Med 2008; 177: 75-81.

68 Kubo H, Nakayama K, Yanai M, et al. Anticoagulant therapy for idiopathic pulmonary fibrosis. Chest 2005; 128: 1475-1482.

69 Demedts M, Behr J, Buhl R, et al. High-dose acetylcysteine in idiopathic pulmonary fibrosis. N Engl J Med 2005; 353: 2229-2242.

70 Azuma A, Nukiwa T, Tsuboi E, et al. Double-blind, placebocontrolled trial of pirfenidone in patients with idiopathic pulmonary fibrosis. Am J Respir Crit Care Med 2005; 171: 1040-1047.

71 Raghu G, Brown KK, Bradford WZ, et al. A placebo-controlled trial of interferon $\gamma-1 \mathrm{~b}$ in patients with idiopathic pulmonary fibrosis. $N$ Engl J Med 2004; 350: 125-133.

72 Spagnolo P, Del Giovane C, Luppi F, et al. Non-steroid agents for idiopathic pulmonary fibrosis. Cochrane Database Syst Rev 2010; 9 : CD003134.

73 Taniguchi $\mathrm{H}$, Kondoh $\mathrm{Y}$, Ebina $\mathrm{M}$, et al. The clinical significance of $5 \%$ change in vital capacity in patients with idiopathic pulmonary fibrosis: extended analysis of the pirfenidone trial. Respir Res 2011; 12: 93.

74 du Bois RM, Weycker D, Albera C, et al. Ascertainment of individual risk of mortality for patients with idiopathic pulmonary fibrosis. Am J Respir Crit Care Med 2011; 184: 459-466.

75 du Bois RM, Weycker D, Albera C, et al. Forced vital capacity in patients with idiopathic pulmonary fibrosis: test properties and minimal clinically important difference. Am J Respir Crit Care Med 2011; 184: 1382-1389.

76 Raghu G, Collard HR, Anstrom KJ, et al. Idiopathic pulmonary fibrosis: clinically meaningful primary endpoints in phase 3 clinical trials. Am J Respir Crit Care Med 2012; 185: 1044-1048.

77 Bria E, Gralla RJ, Raftopoulos H, et al. Magnitude of benefit of adjuvant chemotherapy for non-small cell lung cancer: metaanalysis of randomized clinical trials. Lung Cancer 2009; 63: 50-57.

78 Arriagada R, Bergman B, Dunant A, et al. Cisplatin-based adjuvant chemotherapy in patients with completely resected non-small-cell lung cancer. N Engl J Med 2004; 350: 351-360.

79 Winton $\mathrm{T}$, Livingston R, Johnson D, et al. Vinorelbine plus cisplatin vs. observation in resected non-small-cell lung cancer. $N$ Engl J Med 2005; 352: 2589-2597.

80 Sederholm C, Hillerdal G, Lamberg K, et al. Phase III trial of gemcitabine plus carboplatin versus single-agent gemcitabine in the treatment of locally advanced or metastatic non-small-cell lung cancer: the Swedish Lung Cancer Study Group. J Clin Oncol 2005; 23: $8380-8388$.

81 Douillard JY, Rosell R, De Lena M, et al. Adjuvant vinorelbine plus cisplatin versus observation in patients with completely resected stage IB-IIIA non-small-cell lung cancer (Adjuvant Navelbine International Trialist Association [ANITA]): a randomised controlled trial. Lancet Oncol 2006; 7: 719-727.

82 Mok TS, Wu YL, Thongprasert S, et al. Gefitinib or carboplatinpaclitaxel in pulmonary adenocarcinoma. N Engl J Med 2009; 361 947-957.

83 Reck M, von Pawel J, Zatloukal P, et al. Phase III trial of cisplatin plus gemcitabine with either placebo or bevacizumab as first-line therapy for nonsquamous non-small-cell lung cancer: AVAil. J Clin Oncol 2009; 27: 1227-1234.

84 Ciuleanu T, Brodowicz T, Zielinski C, et al. Maintenance pemetrexed plus best supportive care versus placebo plus best supportive care for non-small-cell lung cancer: a randomised, double-blind, phase 3 study. Lancet 2009; 374: 1432-1440.

85 Lee DH, Park K, Kim JH, et al. Randomized phase iii trial of gefitinib versus docetaxel in non-small cell lung cancer patients who have previously received platinum-based chemotherapy. Clin Cancer Res 2010; 16: 1307-1314.

86 Scagliotti GV, Krzakowski M, Szczesna A, et al. Sunitinib plus erlotinib versus placebo plus erlotinib in patients with previously 
treated advanced non-small-cell lung cancer: a phase III trial. J Clin Oncol 2012; 30: 2070-2078.

87 Cappuzzo F, Ciuleanu T, Stelmakh L, et al. Erlotinib as maintenance treatment in advanced non-small-cell lung cancer: a multicentre, randomised, placebo-controlled phase 3 study. Lancet Oncol 2010; 11: 521-529.

88 Herbst RS, Sun Y, Eberhardt WE, et al. Vandetanib plus docetaxel versus docetaxel as second-line treatment for patients with advanced non-small-cell lung cancer (ZODIAC): a double-blind, randomised, phase 3 trial. Lancet Oncol 2010; 11: 619-626.

89 Paz-Ares L, de Marinis F, Dediu M, et al. Maintenance therapy with pemetrexed plus best supportive care versus placebo plus best supportive care after induction therapy with pemetrexed plus cisplatin for advanced non-squamous non-small-cell lung cancer (PARAMOUNT): a double-blind, phase 3, randomised controlled trial. Lancet Oncol 2012; 13: 247-255.

90 Rosell R, Carcereny E, Gervais R, et al. Erlotinib versus standard chemotherapy as first-line treatment for european patients with advanced EGFR mutation-positive non-small-cell lung cancer (EURTAC): a multicentre, open-label, randomised phase 3 trial. Lancet Oncol 2012; 13: 239-246.

91 Cohen AH, Bradford WZ, Glasscock KF, et al. Interpreting Outcomes in Therapeutic Clinical Trials in Idiopathic Pulmonary Fibrosis: Benchmarks for Establishing a Clinically Meaningful Benefit. Thematic poster presented at Pulmonary Fibrosis Foundation IPF Summit; December 1-3, 2011; Chicago, IL, USA. 